Jpn J Human Genet 42, 217-223, 1997

\title{
A KERATIN K10 GENE MUTATION IN A JAPANESE PATIENT WITH EPIDERMOLYTIC HYPERKERATOSIS
}

\author{
Kazuo Nomura,,${ }^{1, *}$ Xianmin MenG,${ }^{1}$ Kaoru UmeKI, ${ }^{1}$ Katsuto TamaI,${ }^{1}$ \\ Daisuke SAWAmUra, ${ }^{1}$ Isao HaShImoto, ${ }^{1}$ and Tomoko KIKUCHI ${ }^{2}$ \\ ${ }^{1}$ Department of Dermatology, Hirosaki University School of Medicine, \\ 5 Zaifu-cho, Hirosaki 036, Japan \\ ${ }^{2}$ Division of Dermatology, Yuri Kumiai Sogo Hospital, \\ 38 Kawaguchi Yago, Honjou 015, Japan
}

\begin{abstract}
Summary Epidermolytic hyperkeratosis (EHK), or bullous congenital ichthyosiform erythroderma, is characterized by generalized erythroderma, ichthyosiform skin and blistering, and is caused by an aberration of the keratin intermediate filaments. In this study, we examined keratin $\mathrm{K} 10$ and 1 gene mutations in a Japanese EHK patient who had severe ichthyosiform erythroderma at birth and developed subsequent blistering. The patient had a $\mathrm{G}$ to A transition at codon 156 of the keratin $\mathrm{K} 10$ gene, which resulted in an arginine (Arg) $\rightarrow$ histidine (His) substitution in the helix initiation peptide of the highly-conserved $1 \mathrm{~A}$ domain in keratin $\mathrm{K} 10$. This is the first mutation report of a Japanese patient with EHK, although the position and mode of the mutation identified here did not differ from those in reported Western cases.

Key Words epidermolytic hyperkeratosis, keratin, K10, gene mutation
\end{abstract}

\section{INTRODUCTION}

Epidermolytic hyperkeratosis (EHK), or bullous congenital ichthyosiform erythroderma, is a rare autosomal dominant genetic skin disease (MIM \#113800) (McKusick, 1994) and is characterized by generalized erythroderma, ichthyosiform skin and blistering. The prevalence of the disease is approximately $1: 300,000$. In Japan, 22 patients in 12 families, and 73 sporadic cases have been reported in the medical literature (Naruse et al., 1992). Ultrastructural observations have revealed the presence of clumps of keratin filaments in the suprabasal cells of patients with EHK (Anton-Lamprecht, 1983). Therefore, disruption of keratin has been assumed to be a primary genetic defect in the pathogenesis of this disease. The results of a keratinocyte transfection study indicated that the helix initiation and termination

Received October 31, 1996; Revised version accepted December 26, 1996.

* To whom correspondence should be addressed: Department of Dermatology, Aomori Prefectural Central Hospital, 2-1-1 Higashi-Tsukurimichi, Aomori 030, Japan. 
peptide portions in the helical rod domain play important roles in the composition of the keratin network (Coulombe et al., 1990). Transgenic mice expressing a mutant keratin 10 gene had the EHK phenotype (Fuchs et al., 1992). Furthermore, abnormal keratin $\mathrm{K} 10$ and $\mathrm{Kl}$ network formation has been observed electron-microscopically and immunohistochemically in patients with EHK (Ishida-Yamamoto et al., 1992). All of the above observations indicate strongly that, essentially, keratin aberration is responsible for the EHK phenotype. Indeed, several different types of keratin gene mutation have been reported in EHK patients so far (McLean and Lane, 1995). In this paper, we describe a keratin K10 gene mutation (Arg156His) in a Japanese patient with EHK. The mutation position was in the highly conserved $\mathrm{N}$-terminus of the rod domain in the keratin K10. This is the first mutation report of a Japanese patient with EHK.

\section{PATIENT AND METHODS}

Patient. The patient, a girl, was first seen at our clinic at the age of 5 years. She had burn-like erythema with scales over the whole body at birth. Thereafter she developed blistering, although the frequency of the blistering decreased remarkably with age. Physical examination revealed extensive erythroderma, ichthyosiform skin with scales and hyperkeratosis, particularly on her nape, elbow, knee and abdomen (Fig. 1). Flaccid bullas were seen on her left knee and right dorsal foot (Fig. 2). She had no palmoplantar keratoderma. Her parents are from Akita prefecture in Japan. Her paternal grandmother and maternal grandmother are cousins and paternal grandmother and maternal grandfather are another

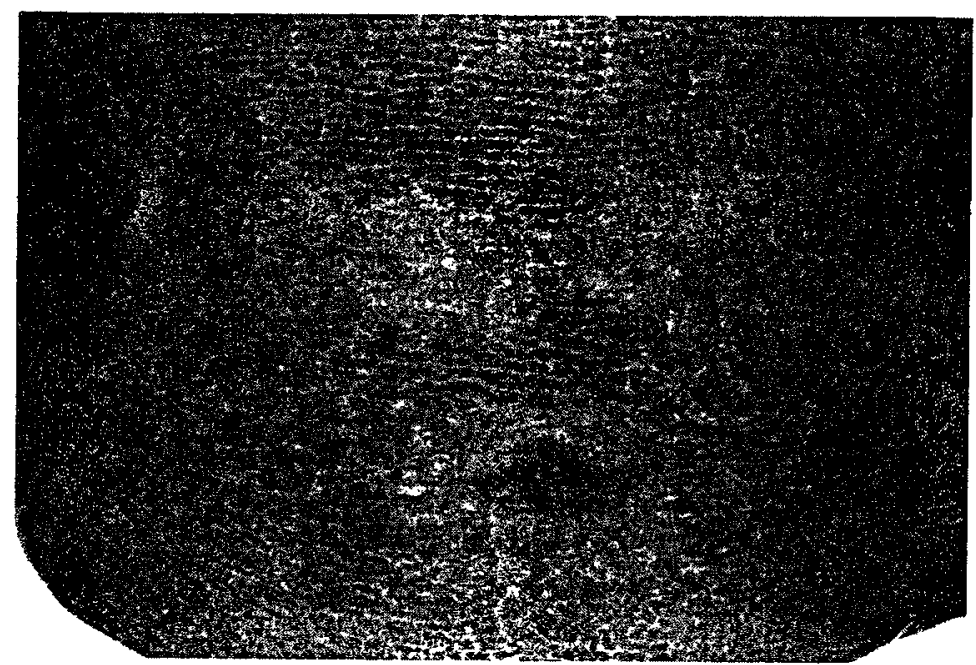

Fig. 1. Clinical picture. Erythroderma and ichthyosiform lesion on the patient's abdomen. 


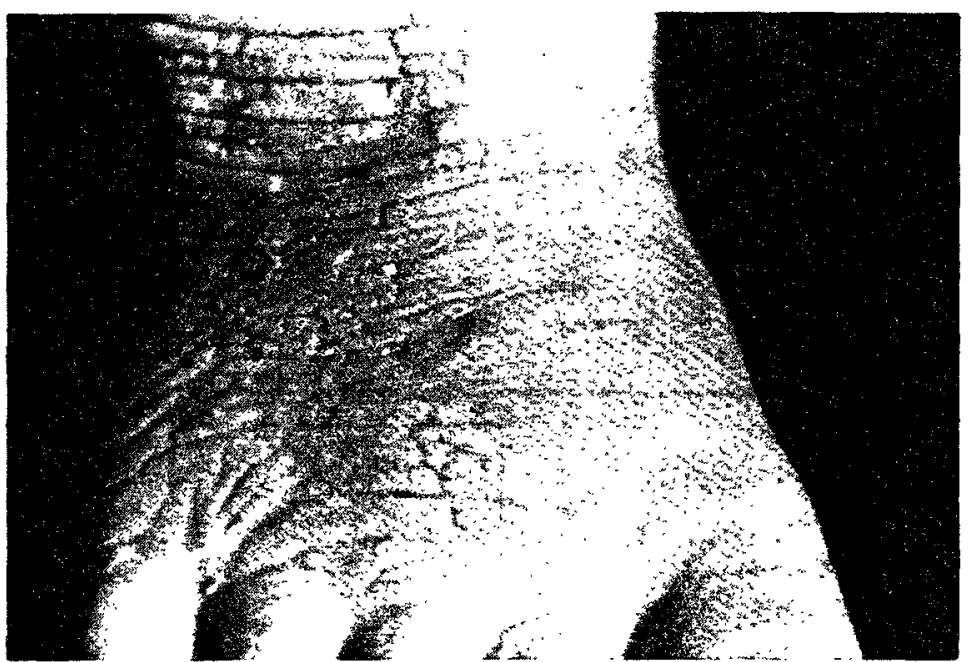

Fig. 2. Clinical picture. Blistering on the dorsal region of the patient's foot.

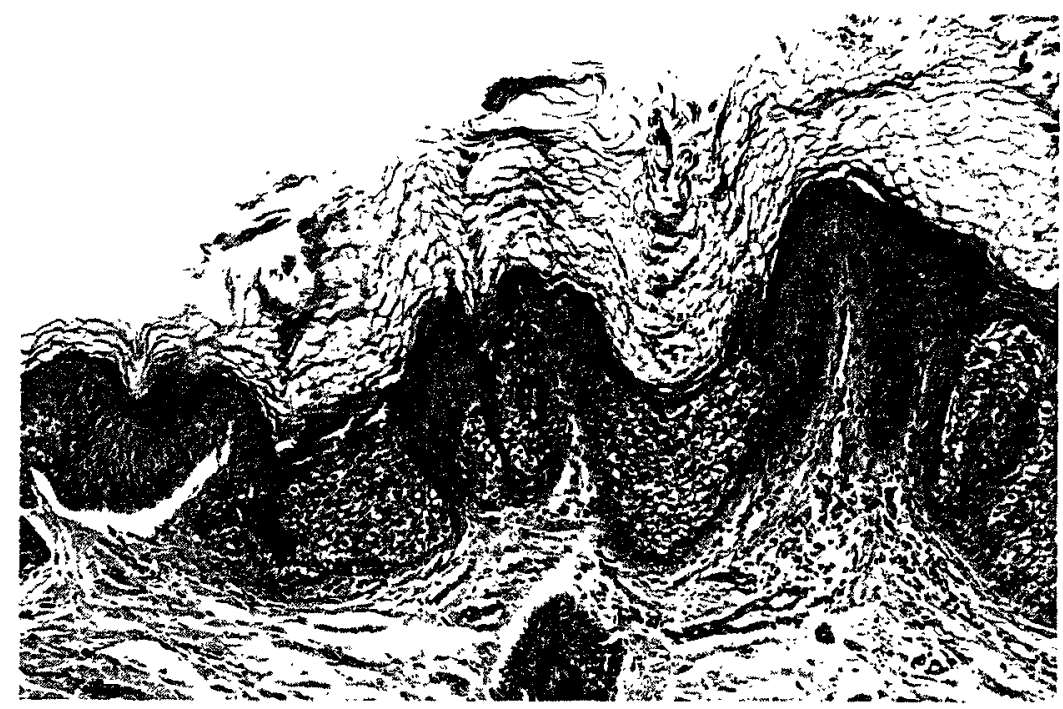

Fig. 3. Histological features of the skin specimen. Hyperkeratosis and prominent vacuolar degeneration of the epidermis.

cousins. Her parents and two siblings were not affected. Histological examination of a skin specimen showed a prominent vacuolar degeneration in the granular layer of the epidermis, indicating so-called "granular degeneration" (Fig. 3). Electron microscopy demonstrated aggregation of tonofilaments and gross keratohyaline granules in the granular layer. Based upon these clinical and histological grounds, she was diagnosed as a sporadic case of EHK. 
Mutation identification. To detect keratin gene mutations in the patient, we used a genomic polymerase chain reaction (PCR) to amplify the keratin K10 and $\mathrm{K} 1$ genes. To simplify the analysis, we focused initially on the regions encoding the $\mathrm{N}$ - and C-termini of the rod domains in keratin $\mathrm{K} 10$ and $\mathrm{K} 1$. Several sets of primers were designed in order to cover these regions. The PCR was performed in a $100-\mu 1$ reaction volume by adding $100 \mathrm{pmol}$ of each primer, $\sim 500 \mathrm{ng}$ template DNA and 2.5 U Taq polymerase (Takara, Japan). The PCR conditions consisted of 30 cycles, comprising denaturation at $94^{\circ} \mathrm{C}$ for $1 \mathrm{~min}$, annealing at $58^{\circ} \mathrm{C}$ for 1 min and extension at $72^{\circ} \mathrm{C}$ for $2 \mathrm{~min}$. The mutation detection enhancement (MDE) method was used to screen for mutation fragments (Keen et al., 1991). Briefly, each PCR product was denatured and annealed, electrophoresed using a polyacrylamide gel (MDE gel, AT Biochem, Rockland, Maine, USA), stained with ethidium bromide, and photographed. The oligonucleotide primers used for amplifying the genes encoding the $\mathrm{N}$ terminus of the $\mathrm{K} 10$ rod domain were $5^{\prime}-\mathrm{TGGAGC}$ TGGTGGTGGCTTTG-3' (exon 1-sense) and 5'-TCACAGTCTTGGTGCCCTGCT-3' (exon 2-antisense). The PCR product was treated with exonuclease I and shrimp alkaline phosphatase to remove residual PCR primers and deoxynucleotide triphosphates, respectively, and sequenced directly using T7 DNA polymerase (Sequenase, Biochemical Corp., Cleveland, Ohio, USA), according to the manufacturer's protocol.

\section{RESULTS}

The MDE method revealed a heteroduplex DNA in the gel only containing

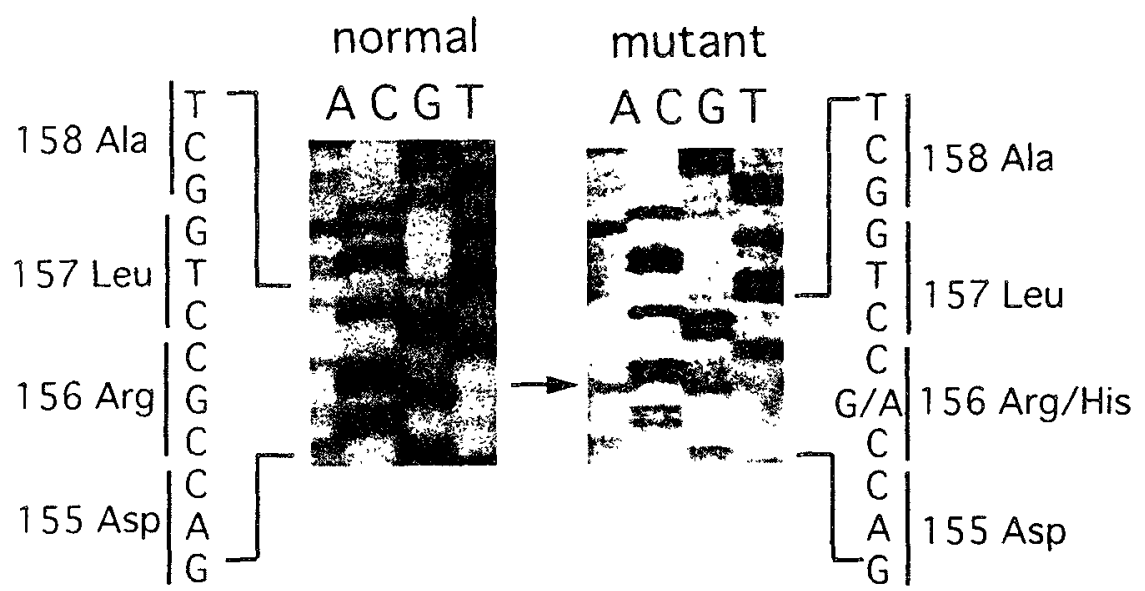

Fig. 4. Nucleotide sequencing of genomic DNA demonstrating a point mutation in one of the keratin K10 alleles of the Japanese EHK patient. Sequencing was carried out directly on the starting PCR-amplified DNA of a fragment containing heteroduplex DNA. The arrows indicate the position of sequence heterogeneity indicating a $\mathrm{G} \rightarrow \mathrm{A}$ transition at codon 156 in one allele. 


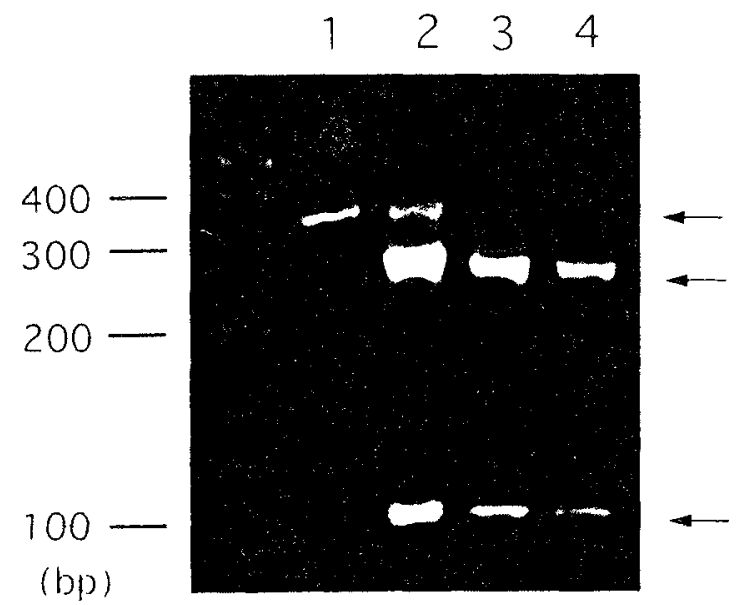

Fig. 5. Confirmation of the point mutation. After digestion of the PCR product with $A C i$, the fragments were resolved by electrophoresis on $2 \%$ agarose gel. Consequently, one undigested fragment of $352 \mathrm{bp}$ and two digested fragments of 260 and $92 \mathrm{bp}$ were produced from the patient's DNA, whereas only two digested fragments were obtained from the DNA of her unaffected parents. 1, Uncut; 2, patient; 3, father; 4, mother.

the heterozygous gene encoding the $\mathrm{N}$-terminus of the keratin $\mathrm{K} 10$ rod domain (data not shown). The patient's parents, who were unaffected, showed no heteroduplex DNA. The starting PCR product containing heteroduplex DNA was subjected directly to DNA sequencing, which revealed a $G \rightarrow A$ transition at the second position of codon 156. The amino acid was deduced to have changed from arginine to histidine (Fig. 4). The mutation led to loss of AciI endonuclease restriction site and was confirmed by the digestion of the PCR product with AciI. The digest resulted in replacement of the $352 \mathrm{bp}$ band by two fragments with predicted sizes of 260 and $92 \mathrm{bp}$ in her unaffected parents, whereas the patient DNA was heterozygous for undigested 352 and digested 260/92 bp bands (Fig. 5). Furthermore, to confirm that the mutation was not a common polymorphism, we examined DNA samples from 40 healthy, unrelated Japanese individuals. The same mutation was not found among any of the 80 alleles examined.

\section{DISCUSSION}

Keratins are the major structural proteins of the epidermis in the skin. These proteins assemble as coiled-coil heterodimers consisting of a specific acidic (type I) and basic (type II) keratin. Dimers undergo further polymerization to form keratin intermediate filaments by an assembly process. Keratins are expressed as pairs in a tissue-specific manner. In the basal cells of the epidermis of the skin, synthesis of keratin K14 (type I) and K5 (type II) predominates, whereas in the 
suprabasal layers of the epidermis, keratins K10 (type I) and K1 (type II) constitute the majority of the cellular protein. Keratin has a central rod domain that contains four largely $\alpha$-helical segments, helix 1A, 1B, 2A and 2B. The rod is flanked by nonhelical head and tail segments that are variable in size and sequence. The helices contain heptad repeats of hydrophobic residues, producing a hydrophobic seal on the helical surface, thus enabling the coiled-coil heterodimerization of parallel aligned molecules of K14 and K5, or K10 and K1 (Steinert and Freedberg, 1991; Cheng et al, 1992).

In this study, we have described a $\mathrm{G}$ to $\mathrm{A}$ transition at codon 156 which resulted in an amino acid change from Arg to His, in a Japanese EHK patient suffering from severe erythrodermic and ichthyosiform skin lesions. This mutation is pathogenic and not polymorphic. We did not observe it in a similar analysis of 40 unrelated Japanese individuals. In the type I keratin family, the amino acid sequence of codons, MQNLNDR, is almost invariant among type I keratins (Fig. 6). In addition, the amino acid position which mutated here is strictly occupied by an Arg. Therefore, substitution of this particular Arg by His at the seventh position of the heptad repeat may have a deleterious effect on this highly conserved region of the keratin K10 molecule. Furthermore, a study on the transfection of mutant Arg156His in keratin K10 into keratinocytes revealed disrupted keratin filament assembly (Syder et al., 1994). Therefore, disruption of this highly conserved sequence is likely to have a deleterious effect on the protein structure. To

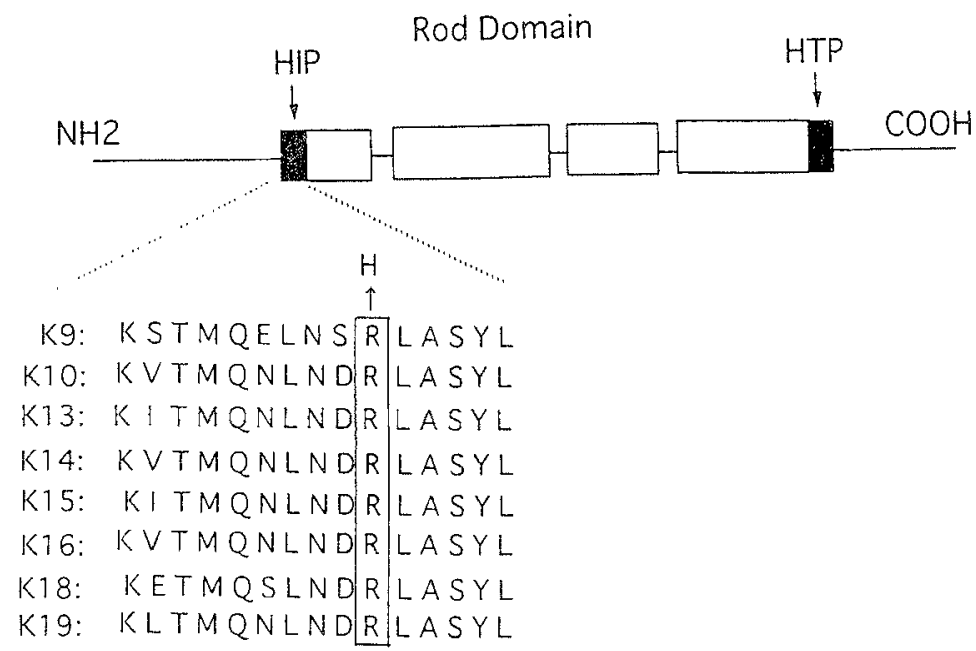

Fig. 6. A highly conserved amino acid sequence in the $1 \mathrm{~A}$ region of type I keratin. Keratin has a central rod domain that contains four largely $\alpha$-helical rod domains (box). Note that the sequence MQNLNDR is highly conserved among type I keratin helix-initiating peptide (HIP). Particularly, the arginine is a strictly conserved hydrophobic amino acid residue of the heptad repeat in the keratin K10 HIP. HTP, helix-terminating peptide. 
date, ten different types of $\mathrm{K} 10$ and six $\mathrm{Kl}$ keratin mutations have been reported in EHK (McLean and Lane, 1995). All of these mutations have clustered in the helix-initiating or terminating region in the domain structure of keratin K10 or K1. In addition, the same Arg residue (Arg156) of keratin K10 was mutated in many reported EHK mutations (Compton, 1994), including our own case, indicating that the Arg residue is structurally important for filament assembly. Thus, the mutation would perturb keratin network formation in the suprabasal cells and lead to skin thickening and blister formation. Finally, the position and mode of the mutation identified here did not differ from those of other reported American cases (Cheng et al., 1992; Rothnagel et al., 1992).

Acknowledgments Part of this work was carried out in the Department of Molecular Genetics, Institute of Cerebronervous Disease, Hirosaki University School of Medicine.

\section{REFERENCES}

Anton-Lamprecht I (1983): Genetically induced abnormalities of epidermal differentiation and ultrastructure in ichthyoses and epidermolysis: pathogenesis, heterogeneity, fetal manifestation and prenatal diagnosis. J Invest Dermatol 81: 149-156

Cheng J, Syder AJ, Yu Q-C, Letai A, Paller AS, Fuchs E (1992): The genetic basis of epidermolytic hyperkeratosis: A disorder of differentiation-specific epidermal keratin genes. Cell 70: $811-816$

Compton JG (1994): Epidermal disease: faulty keratin filaments take their toll. Nature Genet 6: 6-7

Coulombe PA, Chain Y-M, Albers K, Fuchs E (1990): Deletions in epidermal keratins leading to alterations in filament organization in vivo and in intermediate filament assembly in vitro. J Cell Biol 111: 3049-3064

Fuchs E, Esteves RA, Coulombe PA (1992): Transgenic mice expressing a mutant keratin 10 gene reveal the likely genetic basis for epidermolytic hyperkeratosis. Proc Natl Acad Sci USA 89: 6906-6910

Ishida-Yamamoto A, McGrath JA, Juddge MR, Leigh IM, Lane EB, Eady RAJ (1992): Selective involvement of keratins $\mathrm{Kl}$ and $\mathrm{K} 10$ in the cytoskeletal abnormalities of epidermolytic hyperkeratosis (bullous congenital ichthyosiform erythroderma). J Invest Dermatol 99: 119126

Keen J, Lester D, Inglehearn C, Curtis A, Bhattacharya S (1991): Rapid detection of single-base mismatches as heteroduplexes on HydroLink gels. Trends Genet 7: 5

McKusick VA (1994): A catalog of human genes and genetic disorders. In: McKusick VA (ed). Mendelian inheritance in man. 1lth ed. Johns Hopkins University Press, Baltimore, pp 226227

McLean WHI, Lane EB (1995): Intermediate filaments in disease. Curr Opin Cell Biol 7: 118-125

Naruse K, Horikawa T, Tani M (1992): A case of bullous congenital ichthyosiform erythroderma. Hihu Rinsho 34: 863-867 (in Japanese)

Rothnagel JA, Dominey AM, Dempsey LD, Longley MA, Greenhalgh DA, Gange TA, Huber M, Frenk E, Hohl D, Roop DA (1992): Mutations in the rod domains of keratins 1 and 10 in epidermolytic hyperkeratosis. Science 257: 1128-1130

Steinert PM, Freedberg IM (1991): Molecular and cellular biology of keratins. In: Goldsmith LA (ed). Physiology, biochemistry, and molecular biology of the skin. Oxford Univ Press, New York, Oxford

Syder AJ, Yu Q-C, Paller AS, Giudice G, Pearson R, Fuchs E (1994): Genetic mutations in the $\mathrm{K} 1$ and $\mathrm{K} 10$ genes of patients with epidermolytic hyperkeratosis-Correlation between location and disease severity. J Clin Invest 93: 1533-1542

Vol. 42, No. 1, 1997 